International Journal of Advanced Studies in Humanities and Social Science (IJASHSS)

Available online at http://www.ijashss.com

Volume 8, Issue 2 (2019) pp. 187-194

Original Article

\title{
The Influence of Tilt Angle on Heat Loss and Solar Gain in Triple Vacuum Glazing
}

\section{Ramtin Serajian Tehrani1 ${ }^{*}$, Mohsen Faizi², Seyed Bagher Hosseini², Saeid Norouzian Maleki ${ }^{2}$}

\author{
${ }^{1}$ Corresponding Author, M. A. Student, School of Architecture and Environmental Design, \\ University of Science and Technology, Iran \\ ${ }^{2}$ Ph.D, Assistant Professor, School of Architecture and Environmental Design, University of \\ Science and Technology, Iran
}

Received: 24 October 2018, Revised: 05 December 2018, Accepted: 20 December 2018

\section{ABSTRACT}

Hundreds of thousands and perhaps millions of riyals are spent each year for heating and cooling homes and workplaces. Globally, buildings are responsible for approximately 40-45 percent of the total world annual energy consumption. Most of this energy is used for the provision of lighting, heating, cooling and air conditioning. The severity of the climatic conditions in the period considered and the rapid development and increased affluence of recent last decades are among the contributing factors. In particular, much research is focused on thermal energy storage due to heat transfer between the building envelope and the surrounding environment-in order to predict the rate of heat transfer and to develop minimisation strategies. However, the design and construction of modern residential buildings, which are heavily reliant on electrical systems for control of the internal built environment, are causing greater concern. Also, most of the environmental pollution caused by fossil energy are used feeling the need to make use of alternative energy and efforts to minimize the energy dissipation. As a result, local attention is focused on improving energy efficiency for residential buildings. Among the various components of the building envelope, windows require a careful design because much of the heat dissipation occurs there. Windows are responsible for a disproportionate amount of unwanted heat gain and heat loss between buildings and the environment. Solar heat gain plays a major role in determining the thermal performance of a building and increasing or decreasing solar gains can be of crucial importance in design problems. Energy efficient windows should minimize thermal losses as well as air leaks; this is achieved in practice by a combination of different technical solutions, such as multi-layer glazing, low thermal conductivity gas fills, painted glass surfaces, low-emission coatings, edge spacers, and frame materials. An optimal window design with a suitable glazing compound can considerably reduce the energy consumption of air conditioning systems in the residential buildings. In commercial, industrial and public buildings, an optimum window design has the potential to reduce the cost of illumination as well as that of heating, ventilation and air-conditioning (HVAC). Computer simulations are commonly used to provide an expanded scope of systematic study and enable consideration of wide ranges and combinations of parameters. In this study, by computer modeling of the thermal dissipation of impact of tilt angle on the triple vacuum glazing with a thickness of 42 $\mathrm{mm}$, in which a layer of Argon gas used to compare the three main technical factors have been 
examined. These three main factors are heat transfer coefficient, relative rate of heat absorption and solar heat gain coefficient. The model of triple vacuum glazing is based on a commercial product that is available on the consumer market in Tehran. The results show that using triple vacuum glazing reduced more than 70 percent in energy dissipation and 60 degree glass on average in the southern facade of the building to optimize solar gain of solar energy with no apparent increase in thermal dissipation in energy of building.

Keywords: Energy Waste, Triple Vacuum Glazing, Glass Modeling, Heat Transfer, Coefficient.

\section{Introduction}

Every day, sun emits a lot of its energy to the ground and it is very useful for heating the houses (Soltani et al., 1385) and reducing the need for fuel consumption (Gasparella et al., 2011; Noh-Pat et al., 2011; De Giorgi et al., 2011). So, recognizing the role of building components where people live in and the effect degree of each component on total energy consumption all over the country (Poladi and Mojtahedzade, 1382, Khodadadi, 1383, Soltan mohammadi, 1389) and the energy spent on heating the houses in cold season and cooling them in hot seasons for convenient life belongs to housing part (Sadeghiravesh and Tabatabaiee, 1388). So, it is necessary to pay attention to energy loss in this section. Windows provide natural light for inside of the building, create communication with environment, make the building beautiful and prepare an emergency escape route in dangers (Mousavi and Jalali 1385; Mohammad kari, 1388) and make it possible to use solar heat, too (Noh-pat et al., 2011). Window is one of the efficient components of frontage in energy exchange in and out of the building (Mousavi Jalali, 1385) and choosing the type of window is one of the determining parameters of energy consumption in buildings (Gasparella et al., 2011; Hien et al., 2005; Yao and Zhu, 2012; Dalal et al., 2009).
"Glass is a transparent material which has been used as a protective material since up to now to provide light for buildings" (Pouladi and MojtahedZade, 1382: Karimkhani, 1387). The first type of double-glazing glass for optimizing heat loss was made in Sydney University in 1989. Then a double-glazing glass with covers and high heat tolerance was used in mass for the first time in Ulster University. During many years, a lot has been done to optimize heat loss of double-glazing glasses but these researches and studies did not meet the needs for reducing energy consumptions in buildings (Hein et al., 2005). Finally, the idea of triple vaccumglazing (TVG) was introduced by a Swiss team in 2006 and caused efficiency in optimizing heat loss in buildings (Fang et al., 2010).

This research has used computer simulation. Although according to the nature of architecture, needing too much skill and proficiency leads to the limited use of computer based simulation. So, this software must have the most efficient features of a simulation software and must be easy to use (Gheyasi, Mahdavi nia, Tahbaz and Mofidi Shemrani, 1392). WINDOWS 6 has these capabilities to be used in this research.

This research has used a type of standard Low- $\mathrm{E}^{6}$ standard glass with a cover and then it was simulated in software in south facing of the building 
and its angles and index changes were evaluated. The charts related to the changes for different angles were drawn and analytical results were calculated in final part.

\section{Research Method}

This research has used computer simulation. Although according to the nature of architecture, needing too much skill and proficiency leads to the limited use of computer based simulation. So, this software must have the most efficient features of simulation software and must be easy to use (Gheyasi, Mahdavi nia, Tahbaz and Mofidi Shemrani, 1392).

Due to need for separating different parts of the window for simulation of one square meter of triple-glazing glass and measuring the factors related to glass simulation, we have used WINDOWS 6 for its efficiency and capability for our purpose. Reliability of the measures and the results has been proved by various tests and measurements (Smith et al., 2012; Hart et al., 2012). Finally, after gaining the data, findings were changed into charts by Grapher 9 software so that their analysis would be easy.

Simulated Triple-glazing glass (VcoolSClear) was made of standard glasses of Venous companies which provides the glasses for VistaBest company's windows and was used in most buildings of the offices and buildings of Tehran. Table 1 shows the features of three types of simulated glass in 90 degree position toward horizon. Argon layer was $12 \mathrm{~mm}$ as the middle layer and all the glasses were type of Low-E.

Table 1. Technical Features According to Venous Glass Co

\begin{tabular}{ccccccc}
\hline Sc & $\begin{array}{c}\text { Percent of } \\
\text { visible } \\
\text { light }\end{array}$ & $\begin{array}{c}\text { Ratio of } \\
\text { heat-solar } \\
\text { attraction }\end{array}$ & $\begin{array}{c}\text { Relative } \\
\text { ratio } \\
\text { of heat } \\
\text { attraction }\end{array}$ & $\begin{array}{c}\text { Energy } \\
\text { transportation } \\
\text { coefficient } \\
\text { [W/m2.K] }\end{array}$ & $\begin{array}{c}\text { thickness } \\
\text { [mm] }\end{array}$ & $\begin{array}{c}\text { Technical } \\
\text { features } \\
\text { Glass type }\end{array}$ \\
\hline 0.70 & 0.82 & 0.61 & 458.80 & 3.40 & 6 & $\begin{array}{c}\text { Single-glazing } \\
\text { glass }\end{array}$ \\
0.44 & 0.56 & 0.38 & 280.90 & 0.84 & 42 & $\begin{array}{c}\text { Triple-glazing } \\
\text { glass }\end{array}$ \\
\hline
\end{tabular}

\section{Defining Numerical Factors}

Measuring energy efficiency of produced glasses in companies and by the industrial producers is done through heat conductivity coefficients. This factor determines the heat loss ration of the glasses. If this ratio is less, it shows less heat loss form the building. Heat conductivity coefficient of outer side of the building equals to heat power transported from the outer layer with one square meter, if the heat difference of in and out equals one degree. It is calculated by following equation (Shakerinia, 1382):

$$
\mathrm{U}=1 / \mathrm{R}\left[\mathrm{W} /\left(\mathrm{m}^{2} \cdot \mathrm{K}\right)\right] \quad \text { formula } 1
$$

\section{Solar Heat Energy Gain Ratio}

The most efficient way of controlling the amount of solar energy gain at home and office is to stop its entrance into the building. One way is installing external window shades for shadowing on the building. The simplest way for this is 
putting a window with low solar energy gain ratio. The best way for defining solar energy gain ration is in a range of 0 and 1 . It means that 1 is the highest amount of energy gain which can pass the window and 0 is the minimum amount. For example, 0.4 shows that 40 percent of the available solar heat can pass the glass.

\section{Relative Heat Energy Gain Ratio}

This factor shows the amount of heat flux through the window in a sunny and normal day. In fact, this factor is a combination of heat conductivity coefficient and solar heat energy gain. Outside heat degree is 32 degree and inside is 24 degree centigrade and is gained through following equation (Shakerinya, 1382):

RHG $=$ Usummer*(89-75) + SHGC * (230) Formula 2

\section{Findings}

The charts of classified data by WINDOWS 6 by Grapher software is presented below:

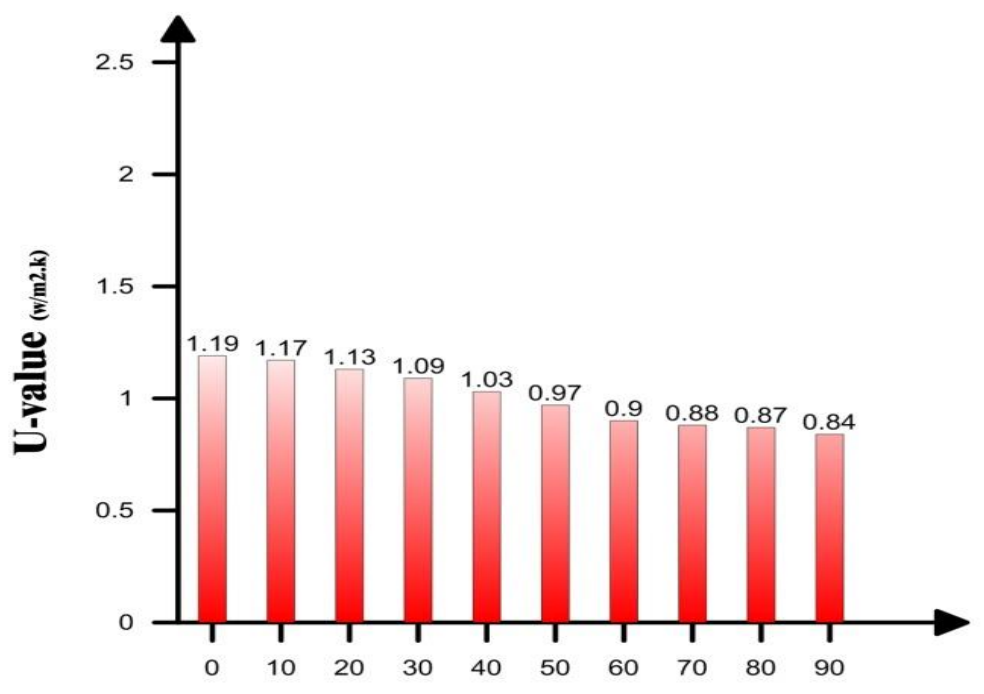

Tilt (Degree)

Chart 1. SHGC Value in Different Angles of Triple-Glazing Glasses

Energy transport coefficient in double-glazing glasses increases by reducing angle of the glass compared to horizon which indicated heat loss increase in glass. Heat loss rapidly increases passing 50 degree angles which lead to serious reduction in stopping energy loss. This case is seen in triple vaccum glazing and this time there has been a sensible change after 50 degree which needs paying attention to this issue in glasses. It means if we need angles change, it should not be more than 50 degree since it causes sudden heat loss and increases the costs.

In addition, comparing triple-glazing and double-glazing glasses, it can be seen that heat conductivity coefficient reduces about 70 percent; so heat conductivity coefficient in triple vaccum glazing with 90 degree is 0.84 which in same situation it will be 3.40 for singleglazing glasses. It shows significant reduction in heat loss in windows by triple-glazing glasses. 


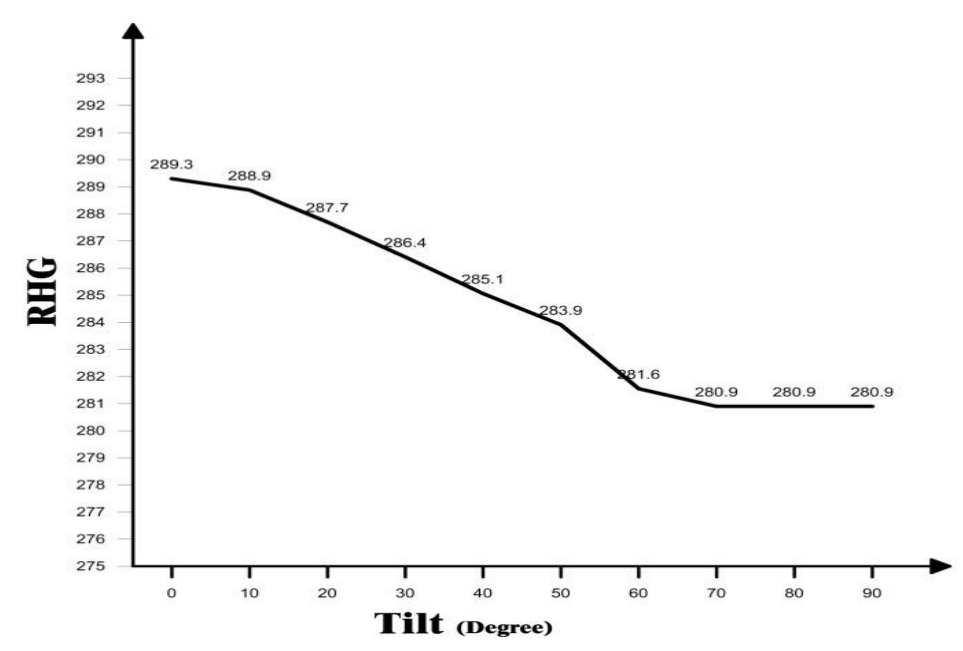

Chart 2. RHG Value in Different Angles of Triple-Glazing Glasses

As can be seen in chart 2, solar heat gain coefficient in triple-glazing glass with reducing glass angles toward horizon shows increase in little conductivity. By setting 60 degree angles heat, gain suddenly increases and can be beneficial or harmful depend on the situation. It means that, for example, in summer in Tehran we have to stop this increase and use glasses with less solar heat gain so that the energy used for cold load in buildings will be reduced. But in winter, we have to use this increase. It means that, by choosing a glass with more heat gain coefficient, we prepare the condition for using solar energy more and reducing energy loss for producing needed heat load.

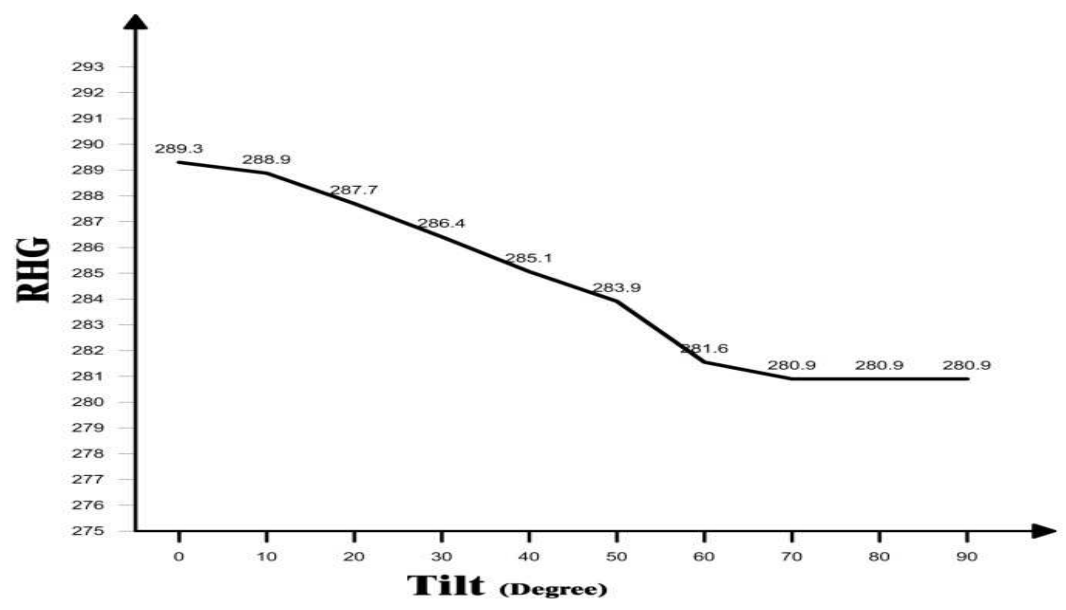

Chart 3. The Amount of RHG in Different Angles in Triple-Glazing Glass

It can be seen that, in chart 3 , the relative heat gain ratio in triple-glazing angles with reduction in glass angles to horizon shows that it indicates increase in heat gain which can pass a window which suddenly increases after passing 60 degree angles. But opposite SHGC, since this factor is measured in a normal sunny day, it can be investigated and in a condition where we need heat gain, we have to reduce glass angle. For example, when we 
use a glass for indirect transportation of light, we can transfer more heat this way.

\section{Conclusion}

As can be said from the beginning, the aim of the present research is getting the best mood of setting windows in facing of the building, so that depending on every situation, we can get the best result. Three factors were investigated and the best choice was chosen. Although economic evaluation was not considered in this research and also the possibility of simulation and testing real sample was not possible laboratory, beneficial results for optimizing fuel consumption and reducing heat loss in building which includes 40 to 45 percent of country consumption is gained.

So, it is necessary to use glasses with low conductive coefficient. Findings of the research indicated that by choosing proper angles of the glass about 60 degree, we can gain more solar energy and save more. In addition, the results indicated that using triple-glazing glass has an effect of more than 70 percent compared to singleglazing glass. But using it is not necessarily useful in every condition. In other words, using the product in primary condition of optimizing solar energy and using natural light in different color spectrum is more common. Using triple-glazing glass is not a proper choice because of low solar energy gain index and heat gain ratio.

Based on geographical condition of Tehran, although angle reduction causes more heat loss but it causes more energy and solar heat entrance into the building. So, using it provides the possibility of using solar energy to the users. It can also be seen in the results that sudden change in 60 degree angle is accompanied by energy gain which leads to energy loss inside the building. This is an important point and we have to pay attention to it and if there is a need to reduce the angles, it must be 50 to 60 degree. So that, in addition to heat gain, heat loss from windows would not change significantly.

This issue becomes reverse when using triple vacuum glazing in hot seasons so that we have to stop heat costs by increasing the angles and putting the window in 90 degree angles and put the glasses with more heat coefficient to stop heat loss from inside the building.

Finally, it must be mentioned that window as one of the most important components of the building is an important factor in preventing heat loss. It is needed to empower and increase the main indexed for stopping heat loss, so there are some strategies that can stop the loss without any costs.

\section{References}

Dalal, R., Naylor, D., \&Roeleveld, D. (2009). "A CFD study of convection in a double glazed window with an enclosed pleated blind". Energy and Buildings41 (11), pp. 1256-1262.

De Giorgi, L., Bertola, V., \&Cafaro, E. (2011). "Thermal convection in double glazed windows with structured gap". Energy and Buildings 43(8), pp. 20342038.

Energy balance and ventral bank statistics. 1386.

Fang, Y., Hyde, T. J., \& Hewitt, N. (2010). "Predicted thermal performance of triplevacuum glazing". Solar Energy 84(12), pp. 2132-2139.

Gasparella, A., Pernigotto, G.,Cappelletti, F., Romagnoni, P., \&Baggio, P. (2011). "Analysisand modelling of window and glazing systems energy performance for awellinsulated residential building". 
Energy and Buildings43 (4), pp. 10301037.

Ghiasi, M., Mahdavi., M. Tahbaz, M and Mofidi Shemirani, S. (1392). The methodology of selecting practical software in architecture. City identity, $7(13)$.

Hart, R., Goudey, H., Arasteh, D \&, .Curcija, D. C. (2012). "Thermal performance impactsof center-of-glass deflections in installed insulating glazing units". Energy and Buildings54, pp. 453-460.

Hien, W. N., Liping, W., Chandra, A. N., Pandey, A. R., \&Xiaolin, W. (2005). "Effects ofdouble glazed facade on energy consumption, thermal comfort and condensation for a typical office building in Singapore". Energy and Buildings37 (6), pp. 563-572.

Window 6 (W6), Research Version (6.3.74) of the Thermal Simulation Software Provided by Lawrence Berkeley National Laboratories, Berkeley, California, USA. Http://windows.lbl.gov/software/window /6/index.html, 2013 (Accessed 10.06.13).

Karimkhani, M (1387). Low Energy glasses (Low-E). Engineers' message. 44.

Khodadai, M. (1382). Optimizing Energy consumption in Dorms of Tehran", third Congress of Fuel consumption in buildings, Tehran, Iran.

Miralikhani, A. (1385). Some points about double glazing glasses in building. 15 (142143).

Mohamadkari, B (1388). Principles and methods of thermal insulating absed on Subject 19 of national building rules. Research center of building. Second edition.
Mousavi M., and Jalali (1385). Studying heat conductivity in multi-glazing windows and investigatinig reduction of loss by using these windows. Fifth congress of optimizing fuel consumption in Buildings. Tehran, Iran.

Noh-Pat, F., Xamán, J., Álvarez, G., Chávez, Y., \&Arce, J. (2011).“Thermal analysis for a typical office building in Singapore". ENERGY AND Building. 37(6). 563-572

Pouladi, A. and Mojtahedzade F. (1382). "Energy saving and reducing heat and cold loss in Great Hotel of Ghazvin", third Congress of optimizing fuel consumption in Tehran buildings, Iran. pp. 453-460. pp. 47-51.

Sadeghi ravesh, M. and Tabatabaiee, S. (1388). Determining thermal comfort limit in dry climate. City indentity, 3(4).

ShaKerinya, A. (1382). Choosing proper windows for accessing energy consumption optimization. Third congress of fuel consumption optimization in buildings, Tehran, Iran.

Smith, N., Isaacs, N., Burgess, J \&, .CoxSmith, I. (2012). "Thermal performance of secondary glazing unit with and without a solar control film $\left(\mathrm{Sns}_{-}-\mathrm{Cu}_{\mathrm{x}} \mathrm{S}\right)$ for using in hot climates". Energy and building. 43 (23). Pp. 704-712

Soltan Mohammadi, Z. (1389). Reducing energy consumption in Buildings with U.P.V.C windows. Building. 8(74).

Soltani, M., Khastooh, B. and Bazmara, H. (1385). Investigating the effect of window type on amount of energy consumption in a sample building in Tehran. Fifth Congress of optimizing fuel consumption in buildings. Teharn, Iran.

Statistics database of Ministry of Mines and Industries, 1386. 
www.cardinalcorp.com Cardinal Glass Industries, Glass Technical Guide.

www.nfrc.org National Fenestration Rating Council.
Yao, J., \& Zhu, N. (2012). "Evaluation of indoor thermal environmental, energy and day lighting performance of thermo tropic windows". Building and Environment49, pp. 283-290.

How to cite this article: Ramtin Serajian Tehrani, Mohsen Faizi, Seyed Bagher Hosseini, Saeid Norouzian Maleki, The Influence of Tilt Angle on Heat Loss and Solar Gain in Triple Vacuum Glazing. International Journal of Advanced Studies in Humanities and Social Science, 2019, 8(2), 187-194.

http://www.ijashssjournal.com/article 84359.html 